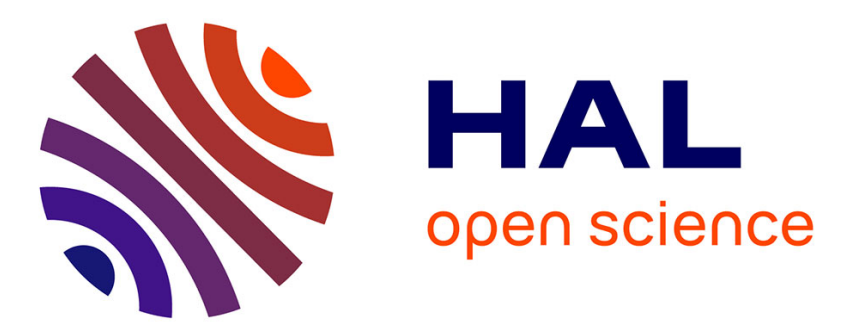

\title{
Prediction of the unsteady turbulent flow in an axial compressor stage. Part 2: Analysis of unsteady RANS and LES data
}

Nicolas Gourdain

\section{- To cite this version:}

Nicolas Gourdain. Prediction of the unsteady turbulent flow in an axial compressor stage. Part 2: Analysis of unsteady RANS and LES data. Computers and Fluids, 2015, vol. 106, pp. 67-78. 10.1016/j.compfluid.2014.09.044 . hal-01104741

\section{HAL Id: hal-01104741 https://hal.science/hal-01104741}

Submitted on 19 Jan 2015

HAL is a multi-disciplinary open access archive for the deposit and dissemination of scientific research documents, whether they are published or not. The documents may come from teaching and research institutions in France or abroad, or from public or private research centers.
L'archive ouverte pluridisciplinaire HAL, est destinée au dépôt et à la diffusion de documents scientifiques de niveau recherche, publiés ou non, émanant des établissements d'enseignement et de recherche français ou étrangers, des laboratoires publics ou privés. 


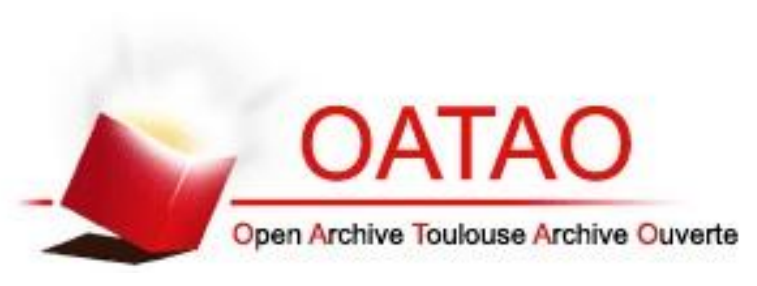

\section{Open Archive Toulouse Archive Ouverte (OATAO)}

OATAO is an open access repository that collects the work of Toulouse researchers and makes it freely available over the web where possible.

This is an author-deposited version published in: http://oatao.univ-toulouse.fr/ Eprints ID: 12305

To link to this article: DOI: 10.1016/j.compfluid.2014.09.044

URL: http://dx.doi.org/10.1016/j.compfluid.2014.09.044

To cite this version: Gourdain, Nicolas Prediction of the unsteady turbulent flow in an axial compressor stage. Part 2: Analysis of unsteady RANS and LES data. (2015) Computers and Fluids, vol. 106. pp. 67-78. ISSN 0045-7930

Any correspondence concerning this service should be sent to the repository administrator: staff-oatao@inp-toulouse.fr 


\title{
Prediction of the unsteady turbulent flow in an axial compressor stage. Part 2: analysis of unsteady RANS and LES data.
}

\author{
Nicolas Gourdain \\ CERFACS, Computational Fluid Dynamics Team, Toulouse, France \\ ISAE, Dpt. of Aerodynamics, Energetics and Propulsion, Toulouse, France \\ Email: Nicolas.Gourdain@isae.fr, Phone: +33561339255
}

\begin{abstract}
This paper presents the analysis of URANS and LES database in a stage of an axial subsonic compressor. Details about numerical methods and comparison with experiments can be found in a companion paper. The analysis here focuses on the transition processes that take place in the rotor and stator rows. In the rotor, LES and URANS show that transition develops at mid-chord and is induced by the adverse pressure gradient. In the stator, the flow behavior is more complex since the transition is influenced by the rotor passing wakes, a laminar separation bubble on the suction side and the accumulation of rotor wakes on the pressure side. The analysis also investigates the unsteady flow patterns at the rotor/stator interface, from mid-span to the casing. In the tip region, LES shows the development of frequencies that are not correlated to the blade passing frequency, while URANS only predicts multiples of the blade passing frequency.
\end{abstract}

Keywords: Large-Eddy Simulation, RANS, rotor/stator interactions, 
laminar-to-turbulent transition 


\section{Nomenclature}

\begin{tabular}{|c|c|}
\hline Latin & Greek, symbols and acronyms \\
\hline$C$ :Blade chord & $\delta:$ :Boundary layer thickness \\
\hline$h:$ Radial height & $\eta$ :Efficiency \\
\hline$H$ :Compressor vein height & $\eta_{K}:$ Kolmogorov length scale \\
\hline$k:$ Turbulent kinetic energy & $\epsilon$ :Dissipation \\
\hline$M$ :Mach number & $\tau$ :Stress tensor \\
\hline$M_{0,1,2}:$ Type of grid (see Table 2 ) & $\pi$ :Total-to-total pressure ratio \\
\hline$n:$ Normal to the wall component & $\nu:$ Kinematic viscosity \\
\hline$p:$ Pressure & $\theta$ :Azimuthal direction, momentum thickness \\
\hline$Q$ :Mass flow & $\omega:$ Compressor rotation speed \\
\hline$r:$ Radial component/direction & $\cdot S G S$ :Sub-grid scale \\
\hline Re :Reynolds number & $\cdot_{0}$ :Inlet value \\
\hline$s:$ Streamwise component & $\cdot_{2}$ :Outlet value \\
\hline$S$ :Curvilinear abscissa or entropy & $\cdot^{+}:$Normalized value at the wall \\
\hline$S_{i j}:$ Strain rate tensor & ? :Resolved field \\
\hline$T:$ Temperature & BPF:Blade Passing Frequency \\
\hline$T u$ :Turbulent intensity $\left(\sqrt{W_{i}^{\prime 2}} /\|W\|\right)$ & LES:Large-Eddy Simulation \\
\hline$W:$ Velocity component (relative frame) & RANS:Reynolds Averaged Navier-Stokes \\
\hline$x:$ Axial direction & RMS:Root Mean Square quantity \\
\hline
\end{tabular}




\section{INTRODUCTION}

The maximization of turbomachinery component efficiency relies on the capabilities of designers to better account for unsteady flow effects. Among these unsteady flows, two categories are of primary interest: rotor/stator interactions, which are periodic in time, and turbulence which is an non periodic phenomenon. As reported by Jahanmiri [12], "the (turbomachinery) flow is a veritable-fluid-dynamical zoo, characterized by separation, reattachment, transition, relaminarization, retransition, etc. all often occurring in the same flow". The flow behavior becomes particularly complex when considering a stage of a turbomachine (for instance a rotor followed by a stator) operating at industrial-relevant conditions (high Reynolds number, compressible flow, etc.). These flows have a strong influence on the state of boundary layers (transition), which is of paramount importance to predict the global performance of a turbomachine in [31].

There are some indications in the literature that the effects of surface curvature, divergence / convergence effects, compressibility, and heat transfer in gas turbines are less significant on transition as compared to free-stream turbulence effects [12]. Previous works also reports that transition [4] as well as the level of losses $[4,1]$ is sensitive to surface roughness. However, since the Reynolds number related to the test case considered in this paper is quite high $\left(\operatorname{Re}=7 \times 10^{5}\right)$, a low level of roughness $(<11 \mu m)^{1}$ should

\footnotetext{
${ }^{1}$ the estimatation of this level of roughness is based on the criterion $k_{s}<\frac{100}{R e} \times C$, with $k_{s}$ the size of roughness and $\mathrm{C}$ the blade chord [4].
} 
not influence the near wall flow. Indeed, transition in the present compressor should be controlled mainly by the free-stream turbulence, pressure gradient and periodic incoming wakes.

Despite some interesting works [11], measurements for transitional flow under real operating conditions (strong accelerating flows, high-freestream turbulence, relaminarization, etc.) remains sparse [12]. Indeed, for this purpose CFD is considered more and more frequently as complementary to experimental campaigns. Different methods to compute unsteady flows have been tested in the literature to study transition phenomena in turbomachinery, such as URANS, LES and DNS [24, 29]. While unsteady RANS usually provides a fair reproduction of the periodic unsteady flows, it only reproduces partially the flow pattern details observed by DNS and LES, especially for the wake dynamics and on the blade suction side [24].

The increase of the computational capability allows nowadays the handling of LES at high Reynolds numbers $\left(R e \approx 10^{6}\right)$, in complex geometries representative of industrial configurations $[31,32,3,9,20]$. Indeed, LES appears as a very promising way to study transitional flows in turbomachinery components and brings new insights on the flow physics that take place in these machines [23].

This paper proposes thus to compare the results obtained with URANS and LES in an axial compressor stage. For both approaches, the geometry takes into account the whole 3D flow. Data are analyzed at nominal operating conditions with a particular emphasis on the near wall flow, both in 
rotor and stator parts. The paper is organized in five sections. In the first one, a summary of the compressor test case is presented along with the numerical method. The second section proposes an analysis of the main flow features, through 2D time-averaged and instantaneous flow fields. The third section deals with the analysis of the near wall flow and focuses on the state of boundary layers through the estimation of turbulent kinetic energy and momentum thickness. The fourth section reports an analysis of the flow at the rotor/stator interface, with the objective to highlight the interactions between rotor and stator parts. The last section proposes an analysis of the transition mechanisms that take place in the stator vane.

\section{NUMERICAL METHOD AND TEST CASE}

A short summary of the test case and numerical method is provided below. More information about the method can be found in the companion paper [7].

The test case considered for this study is the CME2 compressor, originally investigated at the LEMFI laboratory $[6,25]$. This is a single-stage machine with a 30-blades rotor and a 40-vanes stator. The outer tip radius is $0.275 \mathrm{~m}$ and the nominal rotation speed is $6,330 \pm 14 \mathrm{rpm}$ (i.e. $f_{B P F}=3,165 \mathrm{~Hz}$ ). At this rotation speed, the mean Reynolds number based on rotor chord and rotor exit velocity is 700,000 . At the nominal operating point, the mass flow $Q$ is $10.50 \pm 0.1 \mathrm{~kg} / \mathrm{s}$, the total-to-total pressure ratio $\pi$ is 1.15 and the isentropic efficiency $\eta$ is 0.92 . 
Both LES and URANS equations are solved using the CFD code elsA. This software uses a cell centered approach on structured multiblock meshes. More information about the flow solver can be found in [5] for modeling capabilities and in [8] for High-Performance Computing capabilities. For both URANS and LES, convective fluxes are computed with a third-order upwind scheme [27]. Diffusive fluxes are computed with a second-order centered scheme. The turbulent viscosity $\nu_{t}$ is estimated with the two equations model of Menter [21] based on a $k-\omega$ formulation. Transition effects are modelled using two transport equations for the intermittency factor $\gamma$ and the Reynolds number based on the transition momentum thickness $\operatorname{Re}_{\theta, t}[22,16,2]$. For LES, the subgrid scale model is the Wall-Adapting Local Eddy-Viscosity (WALE) model [26].

The time-marching is ensured by a second order Dual Time Stepping method [13], which relies on an implicit scheme (with a scalar Lower-Upper Symmetric Successive Over-Relaxation -LU-SSOR- method [33]). The time step is adapted to the mesh resolution at walls: for URANS, $\Delta t^{+}=\Delta t \times$ $f_{B P F}$ is set to 0.0025 (i.e. 400 time steps per blade passing period, which is sufficient to provide time step independent results [30]) and for LES $\Delta t^{+}=$ 0.00125 (i.e. 800 time steps per blade passing period).

The numerical domain consists of three rotor blades and four stator vanes, in order to respect the natural compressor periodicity. For both URANS and LES, the mesh represents the whole 3D domain, including the tip gap. The number of points corresponding to URANS and LES grids are reported in 
Table 1. The LES grid (M2) corresponds to the finest grid presented in the companion paper, which ensures that mesh criteria recommended in the literature $[28,18]$ to run wall-resolved LES in academic test cases are satisfied $\left(50<\Delta \overline{s^{+}}<150, n^{+}<1\right.$ and $\left.15<r^{+}<40\right)$.

Table 1: Number of points per blade passage and total for the whole configuration.

\begin{tabular}{cccc}
\hline & Rotor & Stator & Whole domain \\
\hline URANS (grid M0) & $1.99 \times 10^{6}$ & $1.69 \times 10^{6}$ & $12.72 \times 10^{6}$ \\
LES (grid M2) & $126.83 \times 10^{6}$ & $107.55 \times 10^{6}$ & $857.28 \times 10^{6}$ \\
\hline
\end{tabular}

\section{ANALYSIS OF TIME-AVERAGED AND INSTANTANEOUS FLOW FIELDS}

URANS and LES time-averaged flow fields, shaded with entropy, are plot in Fig. 1 at $h / H=80 \%$ (since the walls are considered as adiabatic, entropy can be used as an indicator of the level of losses). The fields show losses on the stator pressure side and in the rotor wake region. The increase of entropy production along the stator pressure side can result either in a separation of the boundary layer or in a transport of entropy contained in the wakes preferentially on the pressure side. An overview of the skin friction coefficient is shown in Fig. 2. There is no evidence of a boundary layer separation on the stator pressure side. So it confirms that the entropy accumulation on the stator pressure side is related to the accumulation of incoming rotor wakes that preferentially migrate towards the stator pressure side. Both LES and 
URANS show this effect. However, the wakes predicted with URANS are thicker than those predicted by LES and are associated to a higher level of entropy.

The dashed box in Fig. 1 underlines the location of the losses induced by the tip leakage flow. In the case of LES, this region starts close to the rotor trailing edge and is concentrated in the rotor wake region. In the case of URANS, the influence of the tip leakage flow starts at mid-distance between the rotor and the stator, and it spreads in the whole rotor passage.

(a)

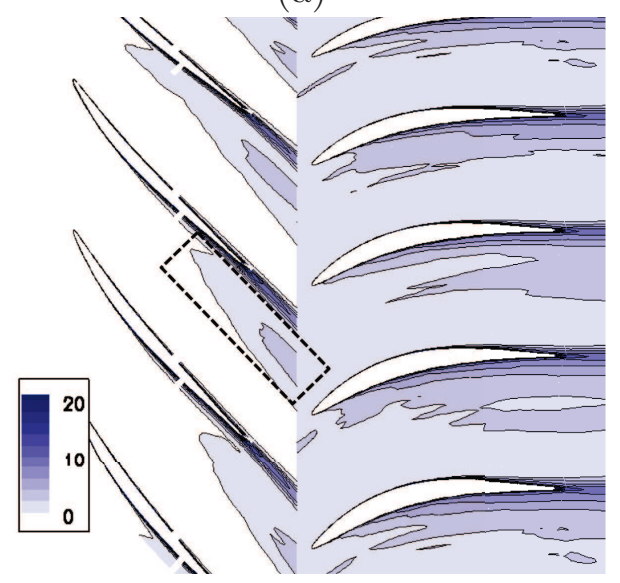

(b)

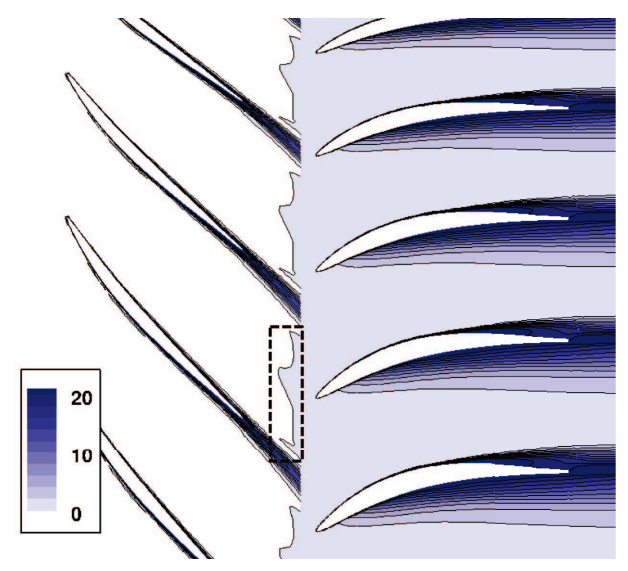

Figure 1: Time-averaged flow field shaded with entropy $S$ at nominal operating conditions, at $h / H=80 \%$ : (a) LES and (b) URANS. [J/kg.K]. The dashed box shows the location of losses induced by the tip leakage flow.

This observation is confirmed in Fig. 3 and Fig. 4, which show instantaneous flow fields, shaded with entropy at two axial positions (rotor/stator interface, $x=75 \mathrm{~mm}$, and downstream the stator, $x=194 \mathrm{~mm}$ ). At the rotor/stator interface, the azimutal extension of the tip leakage flow as pre- 
(a)

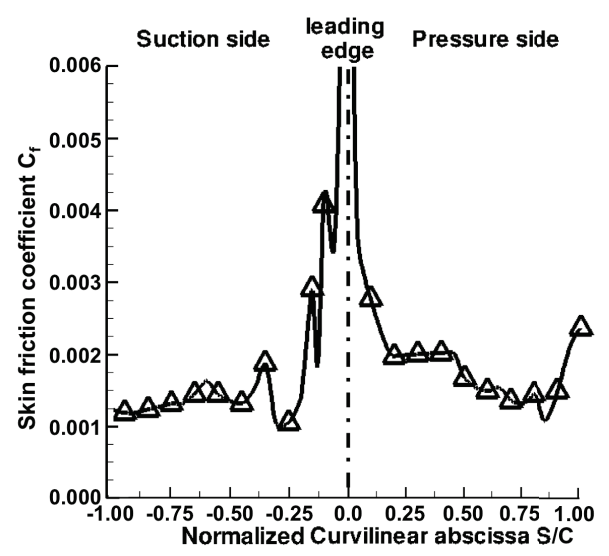

(b)

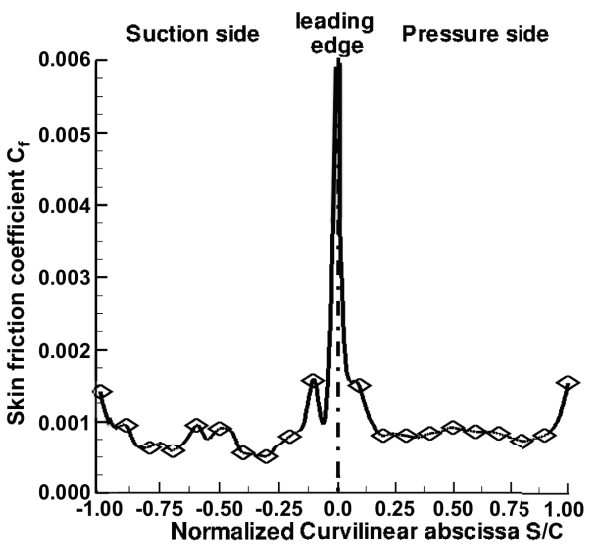

Figure 2: Time-averaged skin friction coefficient, $C_{f}=2 . \tau_{\text {wall }} / \rho(\omega R)_{\text {tip }}^{2}$, from LES data at mid-span $(h / H=50 \%)$ : a) rotor blade and b) stator vane.

dicted by URANS is more important than with LES. On the URANS flow field, the high entropy region extends from the blade suction side (where the tip leakage emerges) to the next rotor blade pressure side. On the LES flow field, the high losses region is restricted to the area close to the rotor suction side and it extends only on half of the rotor passage in the azimuthal direction. At the stator exit, Fig. 4, shows that rotor wakes interacts with stator wakes even far from the stator trailing edge. This interaction is more visible in the case of LES, mainly because the rotor wakes are less quickly dissipated than with URANS. Downstream the stator, both URANS and LES predicts a high-entropy region on the last $40 \%$ of the compressor span, due to a boundary layer separation on the stator suction side (zone 2), induced by the high incidence associated to the rotor tip leakage flow. This separation is 
also observed during the experimental campaign [25]. In the pressure side / casing corner, the high entropy region is related to the accumulation of rotor wakes on the stator pressure side (zone 1).

(a)

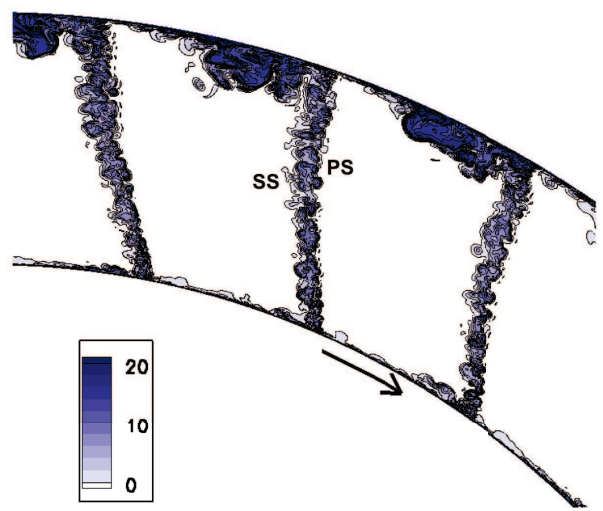

(b)

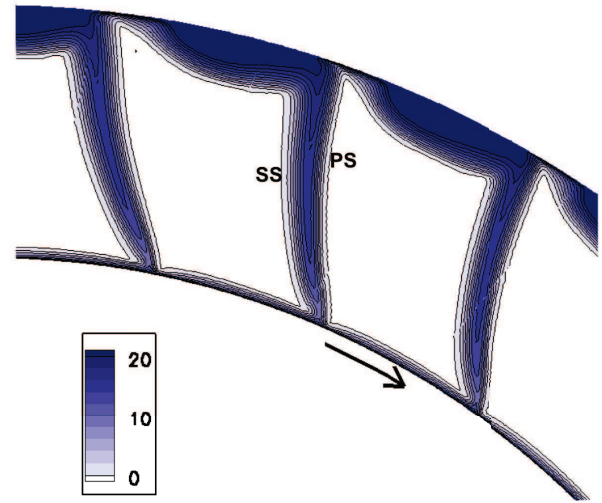

Figure 3: Instantaneous flow field shaded with entropy $S$ at rotor/stator interface $(x=$ $75 \mathrm{~mm}$ ): (a) LES and (b) URANS. [J/kg.K]. The indications of pressure side (PS) and suction side (SS) refer to the rotor.

This qualitative analysis shows that LES and URANS predicts similar flow patterns. However, URANS predicts higher losses than LES, mainly because URANS shows thicker and deeper rotor wakes that propagate downstream.

\section{ANALYSIS OF THE NEAR WALL FLOW}

The time-averaged wall static pressure is plot in Fig. 5, at mid-span $(h / H=50 \%)$. URANS and LES are in good agreement on the suction side of the rotor and only small differences are observed on the pressure side 
(a)

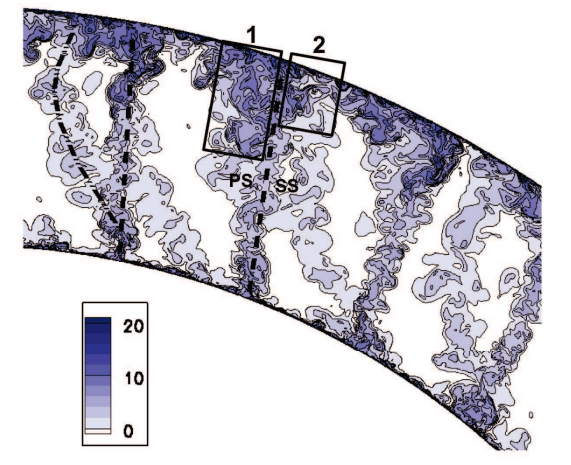

(b)

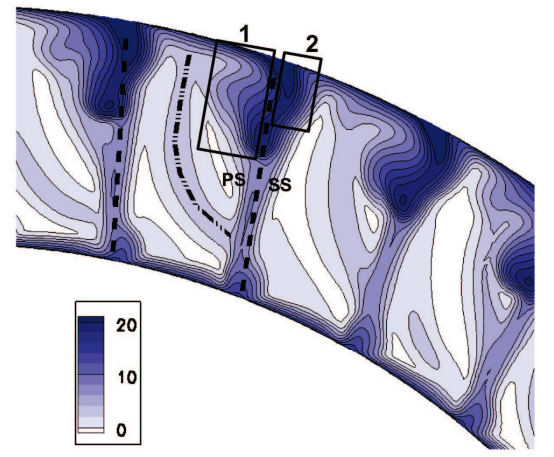

Figure 4: Instantaneous flow field shaded with entropy $S$ downstream the stator ( $x=$ $194 \mathrm{~mm}$ ): (a) LES and (b) URANS. The dashed line shows a stator wake and the dashdotted line corresponds to the rotor wake. [J/kg.K]. The indications of pressure side (PS) and suction side (SS) refer to the stator. The zone 1 refers to the entropy accumulation on the stator pressure side due to rotor wakes and the zone 2 refers to a local boundary layer separation on the stator suction side.

of the rotor (the static pressure profile predicted with URANS is flatter than with LES). On the suction side, the pressure gradient acts in the flow direction from the leading edge to $S / C=0.12$ where a bump is observed. Then the pressure gradient acts against the flow from $S / C=0.20$ until the trailing edge of the blade. The maximum adverse pressure gradient is located from $S / C=0.35$ to $S=0.40$. Similar observations are drawn for the stator: a weak adverse pressure gradient exists on the pressure side from $S / C=0$ to $S / C=0.35$. On the suction side of the stator, the pressure gradient is favorable from $S / C=0$ to $S / C=0.25$ and it becomes unfavorable on the rest of the chord. LES also predict a steep increase of the pressure gradient on the suction side of the stator, at $S / C=0.50$, compliant with a laminar 
separation bubble [14].

(a)

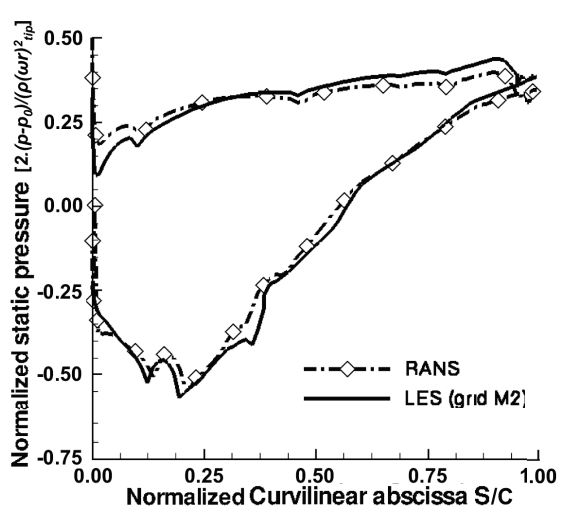

(b)

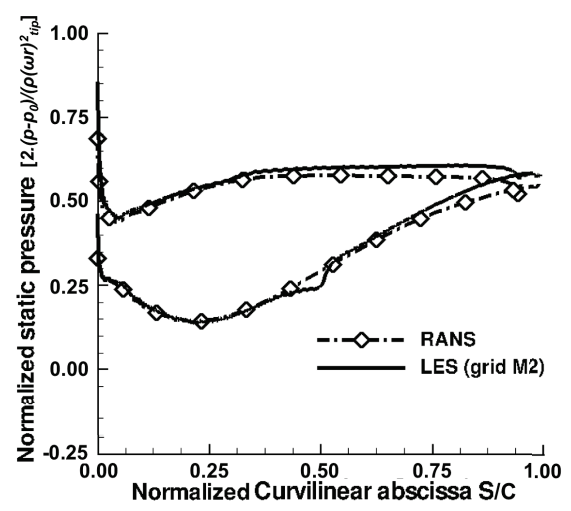

Figure 5: Time-averaged static pressure coefficient, $C_{p}=2 .\left(p_{\text {wall }}-p_{0}\right) / \rho(\omega R)_{t i p}^{2}$, at midspan $(h / H=50 \%)$ : a) rotor blade and b) stator vane. The suction side is the lower curve.

The pressure gradient has an effect on the state of boundary layer, as shown on the production of time-averaged turbulent kinetic energy $\bar{k}$, Fig. 6 . On the rotor suction side, both LES and URANS predict the onset of transition at $S / C=0.40$. On the rotor pressure side, LES shows it at $S / C=0.55$ and URANS shows it at $S / C=0.25$. Such an early transition of the boundary layer with URANS compared to LES has already been reported in the literature [24]. In the case of LES, the transition is located in the region where the adverse pressure gradient is maximum (see Fig. 5). The production of turbulent kinetic energy $\bar{k}$ is moderate and quasi-linear on the pressure side from $S / C=0.50$ until the trailing edge $\left(\bar{k}_{\max } /(\omega r)_{\text {tip }}^{2}=0.005\right)$ compared to the rapid growth on the suction side from $S / C=0.40$ to $S / C=0.45 \mathrm{~mm}$ 
where it reaches $\bar{k}_{\text {max }} /(\omega r)_{\text {tip }}^{2}=0.020$. In the case of URANS, the production of $\bar{k}$ is lower than LES at the transition point on the suction side $\left(\bar{k}_{\text {max }} /(\omega r)_{\text {tip }}^{2}=0.010\right)$ but the decrease of $\bar{k}$ follows the same tendency.

In the stator, LES predicts a similar behavior compared to the rotor one, except that a small peak of $\bar{k}$ is observed at the leading edge due to the incoming rotor wakes $\left(\bar{k}_{\max } /(\omega r)_{\text {tip }}^{2}=0.002\right)$. Then the turbulent kinetic energy vanishes on the suction side until $S / C=0.50$, where transition is observed, $\bar{k}_{\text {max }} /(\omega r)_{\text {tip }}^{2}=0.011$ (this location corresponds to the point where the adverse pressure gradient is maximum). On the stator pressure side, $\bar{k}$ reaches its maximum at $S / C=0.35\left(\bar{k}_{\max } /(\omega r)_{\text {tip }}^{2}=0.005\right)$. The transition point is found closer to the leading edge on the stator pressure side than on the suction side, mainly due to the accumulation of high turbulent activity contained in the rotor wakes that migrates preferentially on the pressure side. The analysis of URANS results show a different behavior: the transition spreads on the suction side from $S / C=0$ to $S / C=0.50$ and on the pressure side from $S / C=0$ to $S / C=0.25$.

Actually, the influence of transition on boundary layers can be observed on the estimation of the Reynolds number based on the momentum thickness, defined as

$$
R e_{\Theta}=\frac{\rho_{\infty} \cdot W_{s, \infty} \cdot \Theta}{\mu_{\infty}}
$$

with $\Theta$ the momentum thickness, as 
(a)

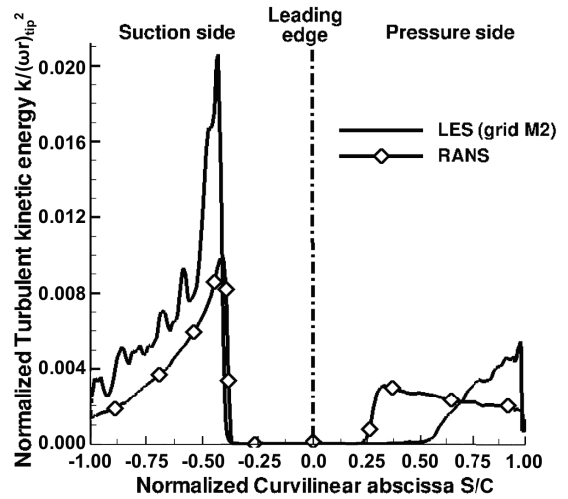

(b)

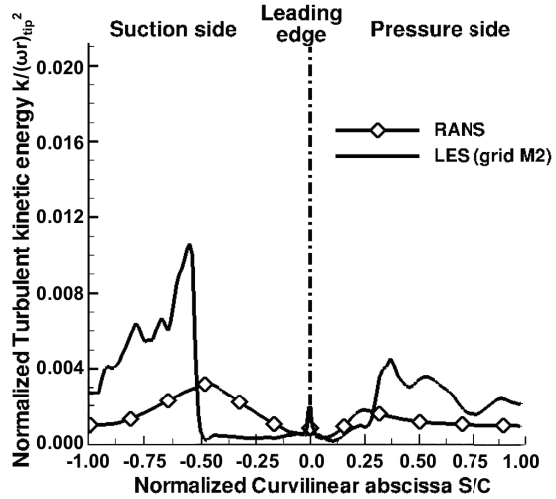

Figure 6: Evolution of the time-averaged turbulent kinetic energy at mid-span $(h / H=$ $50 \%$ ), inside the boundary layer at a wall distance of $100 \mu m(n / \delta \approx 0.03)$ : (a) rotor blade and (b) stator vane.

$$
\Theta=\int_{0}^{+\infty} \frac{\rho W_{s}}{\left(\rho W_{s}\right)_{\infty}}\left(1-\frac{W_{s}}{W_{s, \infty}}\right) d n .
$$

The estimation of the values outside the boundary layer is not trivial for the streamwise component of the velocity $W_{s, \infty}$, the density $\rho_{\infty}$ and the viscosity $\mu_{\infty}$. First it depends on the chord location and then the velocity in the direction normal to the wall does not reach a constant value. The choice has been made to estimate these values by seeking for the maximum in the range $0<n / \bar{\delta}<1.50$. The evolution of $R e_{\Theta}$ based on these estimations is plot in Fig. 7.

In the laminar part of the boundary layers, both LES and URANS predict the same value for $R e_{\Theta}$. However, on the pressure side of the rotor, since transition starts earlier in the URANS simulation $(S / C=0.25)$ than in the 
LES case $(S / C=0.50)$, the value of $R e_{\Theta}$ increases more rapidly. As shown in Table 2 , at $80 \%$ of the rotor chord, the difference on $R e_{\Theta}$ is $83 \%$. The same observation can be done on the rotor suction side but since both URANS and LES find the transition at the same location, the difference is lower at the trailing edge $(+31 \%)$.

(a)

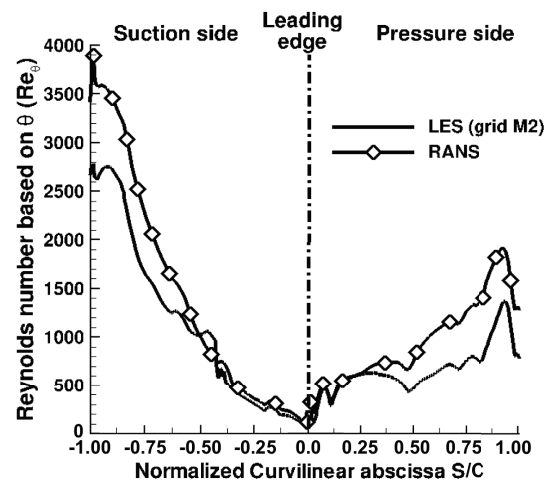

(b)

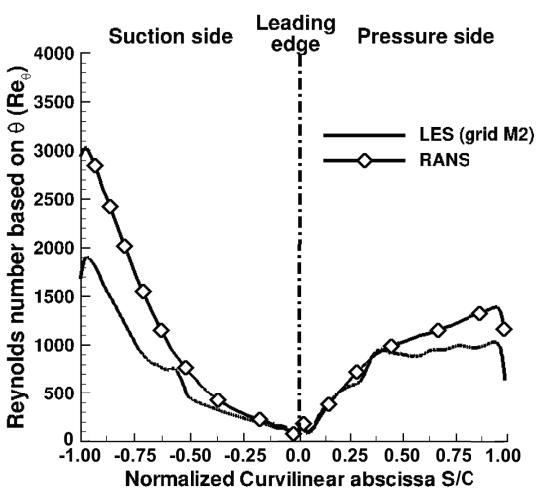

Figure 7: Estimation of the Reynolds number based on the momentum thickness $R e_{\Theta}$, at $h / H=50 \%$ : a) rotor blade and b) stator vane.

\begin{tabular}{lcc|cc}
\hline & \multicolumn{2}{c|}{ ROTOR } & \multicolumn{2}{c}{ STATOR } \\
- & Pressure side & Suction side & Pressure side & Suction side \\
\hline LES & 740 & 2100 & 990 & 1330 \\
URANS & 1360 & 2760 & 1270 & 2120 \\
Difference & $+83 \%$ & $+31 \%$ & $+28 \%$ & $+59 \%$ \\
\hline
\end{tabular}

Table 2: Estimation of the Reynolds number based on the momentum thickness $R e_{\Theta}$, at $80 \%$ of the rotor chord and $h / H=50 \%$.

The analysis is completed by a comparison of the time averaged value of the velocity fluctuations $\overline{W_{i}^{\prime 2}}$, in the boundary layer of the rotor suction 
side, at $S / C=80 \%$. All values are normalized with the streamwise velocity outside the boundary layer $\bar{W}^{2}, \infty$.

As shown in Fig. 8, LES show an anisotropic behavior of the turbulent fluctuations: $\overline{W_{x}^{\prime 2}}{ }_{\max }=2.2 \times{\overline{W_{\theta}^{\prime 2}}}_{\max }=1.6 \times{\overline{W_{r}^{\prime 2}}}_{\max }=0.016 \times \overline{W_{S}^{\prime 2}}$, while URANS finds ${\overline{W_{x}^{\prime 2}}}_{\max }={\overline{W_{\theta}^{\prime 2}}}_{\max }={\overline{W_{r}^{\prime 2}}}_{\max }=0.0075 \times{\overline{W_{S}^{\prime 2}}}_{\infty}$. However, errors partially compensate, so URANS predicts a time-averaged turbulent kinetic energy lower by only $32 \%$ compared to LES.

URANS predicts the peak of turbulent kinetic energy production far to the wall, at $n / \bar{\delta}=0.25$, compared to LES where the maximum value for all velocity components is found below $n / \bar{\delta}=0.07$. The combination "lower production of turbulent kinetic energy + shift of the maximum production point away from the wall" explains the higher sensitivity of the URANS boundary layer to the pressure gradient. This behavior explains the overprediction of the wake depth and thickness in URANS compared to LES and experiments (see the companion paper).

The quality of LES results can also be estimated a posteriori by comparing the resolved turbulence $\widetilde{W_{i}^{\prime 2}}$ (versus) the modeled one $\overline{W_{i}^{\prime 2}}{ }_{S G S}$, approximated as

$$
-{\overline{\left(W_{i}^{\prime} W_{i}^{\prime}\right)}}_{S G S}=2 \cdot \bar{\nu}_{S G S} \times \bar{S}_{i i}
$$

The results shown in Fig. 8 indicate that the modeled components $\overline{W_{i}^{\prime 2}}{ }_{S G S}$ are lower by two order of magnitude than the resolved ones (the modeled part 
$\bar{k}_{S G S}$ represents less than $2 \%$ of the mean resolved kinetic energy $\left.\bar{k}\right)$. Indeed, LES resolves most of the turbulent fluctuations in the boundary layers.

(a)

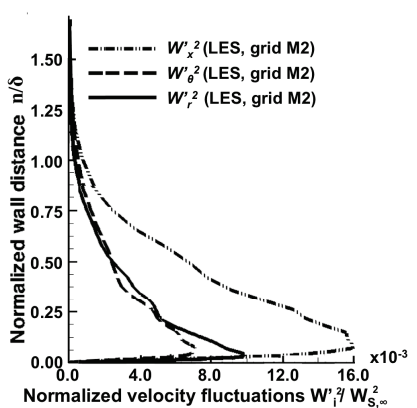

(b)

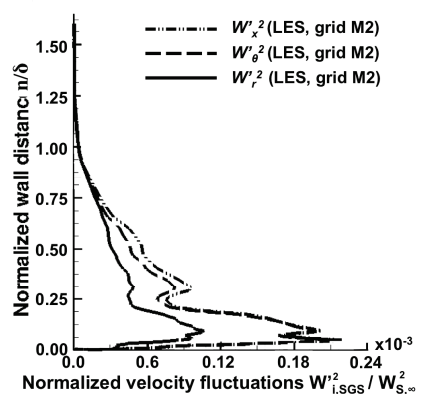

(c)

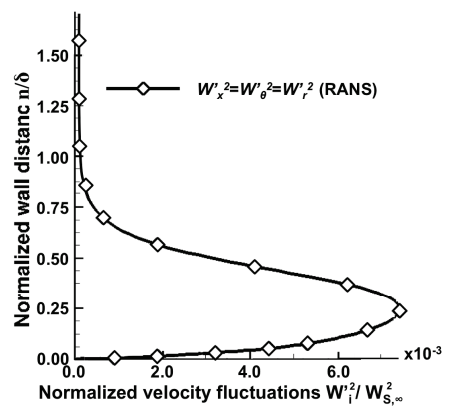

Figure 8: Time averaged fluctuations of the velocity components $\overline{W_{i}^{\prime 2}} / \overline{W_{S}^{2}}$ in the rotor boundary layer at $h / H=50 \%$ and $S / C=80 \%$ : a) LES, resolved components $\overline{W_{i}^{\prime 2}}$, b) LES, modeled components $\overline{W_{i}^{\prime 2}}{ }_{S G S}$ and c) URANS, modeled components (isotropic turbulence model).

\section{ANALYSIS OF THE FLOW AT THE ROTOR/STATOR INTER-}

\section{FACE}

A comparison of axial velocity signals as a function of time and azimuth is shown at mid-span of the rotor/stator interface, Fig. 9. Both URANS and LES show the same flow patterns: the four horizontal strips correspond to the velocity deficit due to stator potential effects and the three diagonal strips are related to the rotor wakes. The velocity deficit increases due to a cumulative effect when the rotor wakes interact with the stator potential effect. 
(a)

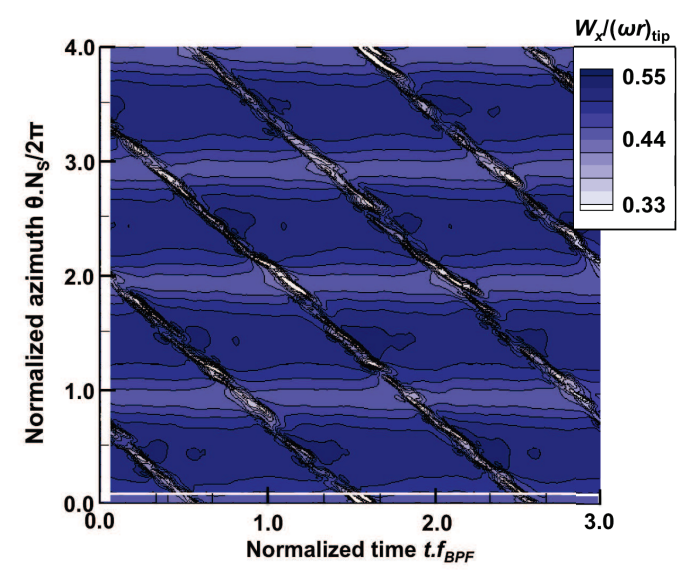

(b)

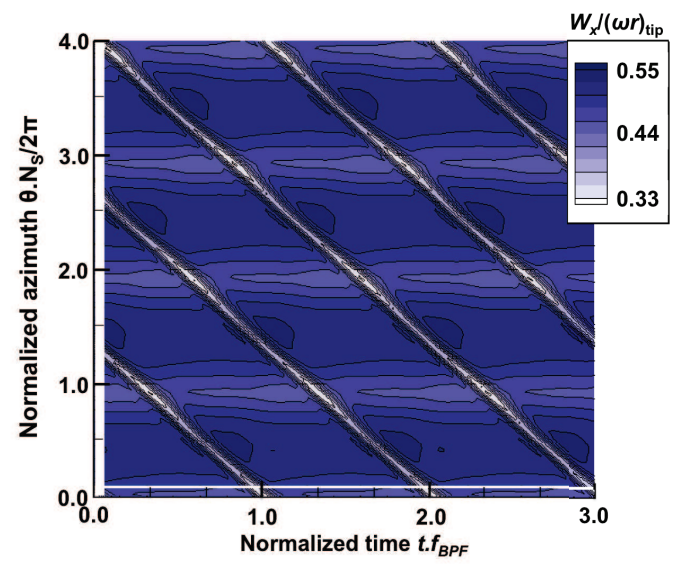

Figure 9: Signal of axial velocity $W_{x} /(\omega r)_{t i p}=f(\theta, t)$ at the rotor/stator interface $(x=$ $75 \mathrm{~mm})$ at $h / H=50 \%$ : a) LES and b) URANS.

In turbomachinery, time-dependent signals can be decomposed in three parts, such as

$$
W_{i}(x, \theta, r, t)=\overline{W_{i}}(x, \theta, r)+W_{i}^{p}(x, \theta, r, t)+W_{i}^{\prime}(x, \theta, r, t)
$$

In the reference frame, the term $\overline{W_{i}}$ represents the steady part of the signal (e.g. stator potential effects), the term $W_{i}^{p}$ represents the periodic part of the unsteadiness (e.g. rotor wakes) and the term $W_{i}^{\prime}$ is related to turbulent fluctuations (with $\overline{W_{i}^{\prime}}=0$ ). In RANS, the term $W_{i}^{\prime}$ can be directly estimated from the turbulent kinetic energy, such as $W_{i}^{\prime 2}=2 / 3 \times k$. In LES the term $W_{i}^{\prime}$ is resolved, except a part provided by the SGS model (which is small in the present case, $\left.\bar{k}_{S G S}<0.02 \times \bar{k}\right)$.

Figure 10 shows the square of the unsteady part of the axial velocity $W_{x}^{\prime \prime 2}$, 
defined as

$$
W_{x}^{\prime \prime 2}(\theta, t)=\left[W_{x}(\theta, t)-\overline{W_{x}}(\theta)\right]^{2}=\left[W_{i}^{p}(\theta, t)+W_{i}^{\prime}(\theta, t)\right]^{2} .
$$

The term $W^{\prime \prime 2}$ measures thus the total unsteadiness of the flow: both periodic (induced by rotor/stator interactions) and turbulent fluctuations. As expected, the unsteadiness in RANS exhibits a periodic behavior which is correlated with the passage of the rotor blades while LES shows a more complex behavior. However, both approaches predict similar flow features. At mid-span, the flow unsteadiness is contained mainly in the rotor wakes, with $W_{x}^{\prime \prime 2}>3.10^{-3} \times(\omega . r)_{t i p}^{2}$. Close to the casing, both URANS and LES shows that flow unsteadiness increases in the passage between two rotor wakes due to the tip leakage flow, $W_{x}^{\prime \prime 2} \approx 1 \cdot 10^{-3} \times(\omega \cdot r)_{\text {tip }}^{2}$ ("bubbles" between the rotor wakes in Fig. 10(b-d)). LES shows that this unsteady flow region remains close to the rotor wakes while URANS predicts the tip leakage flow is shifted towards the middle of the rotor passage.

Actually, another difference between URANS and LES data comes from the spectral content, which is highlighted by Fast Fourier Transform of axial velocity signals in Fig. 11. URANS shows only harmonics of the Blade Passing Frequency $(B P F=3,165 \mathrm{~Hz})$ at $h / H=50 \%$ and $h / H=80 \%$. At mid-span, the fifth harmonic of the BPF (18,990 Hz) still represents $20 \%$ of the energy contained in the BPF. From mid-span to the near casing region, URANS predicts that the energy of the BPF increases by $5 \%$ close to the 
(a)

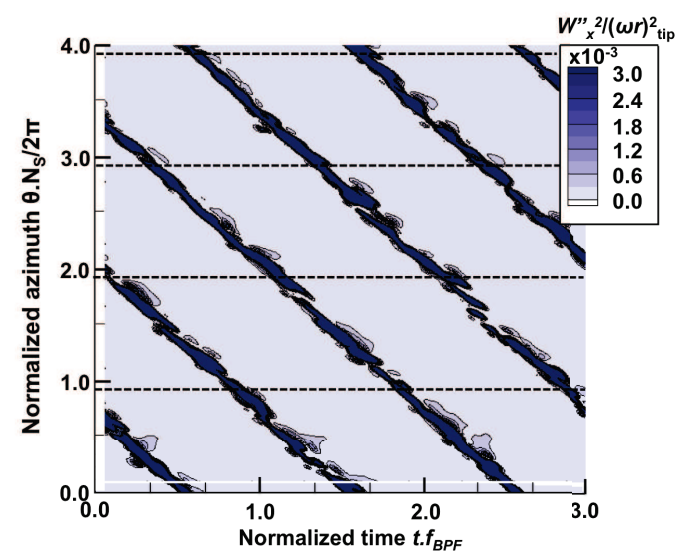

(c)

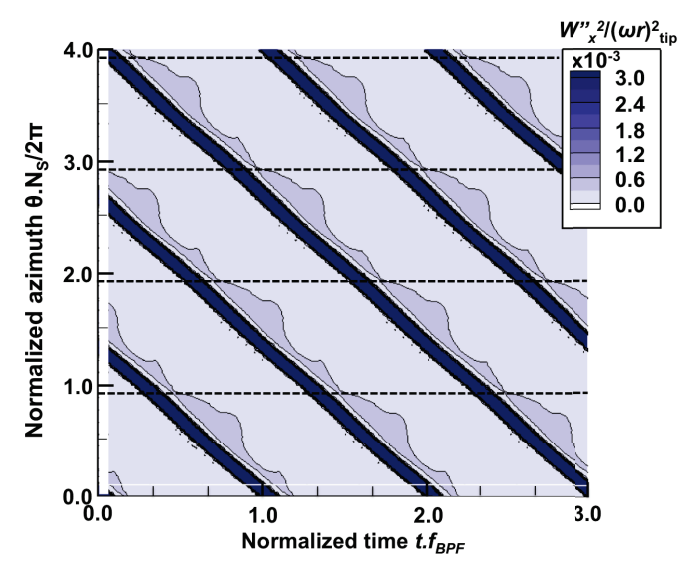

(b)

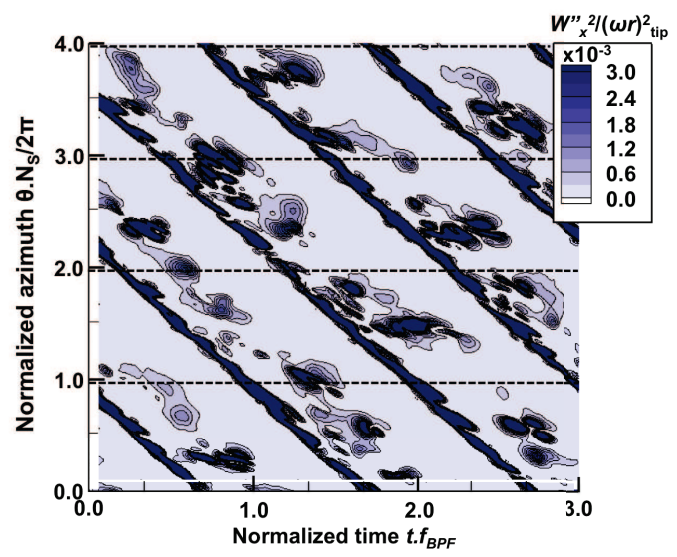

(d)

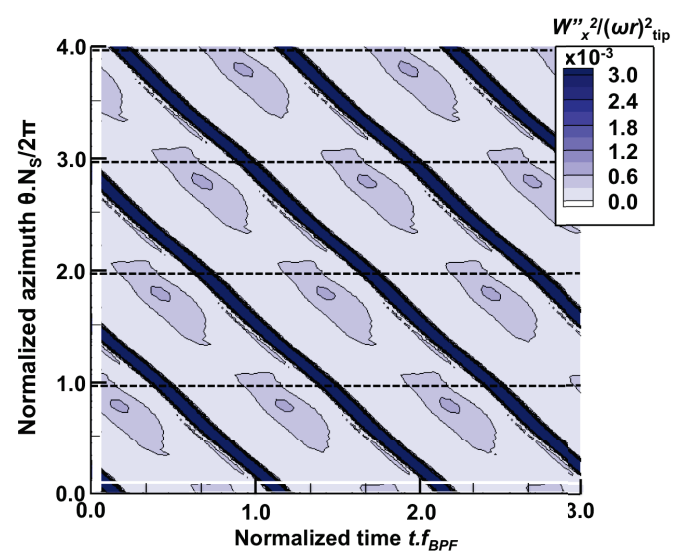

Figure 10: Square of the unsteady part of the axial velocity $W_{x}^{\prime \prime 2}(\theta, t)$, probed at the rotor/stator interface $(x=75 \mathrm{~mm})$ : a) LES at $h / H=50 \%$, b) LES at $h / H=80 \%$, c) URANS at $h / H=50 \%$ and d) URANS at $h / H=80 \%$. The dashed line shows the position of the stator leading edges.

casing while the energy contained in higher harmonics decreases.

The frequencies observed in the LES are not only multiple of the BPF. At mid-span $(h / H=50 \%)$ : 
(a)

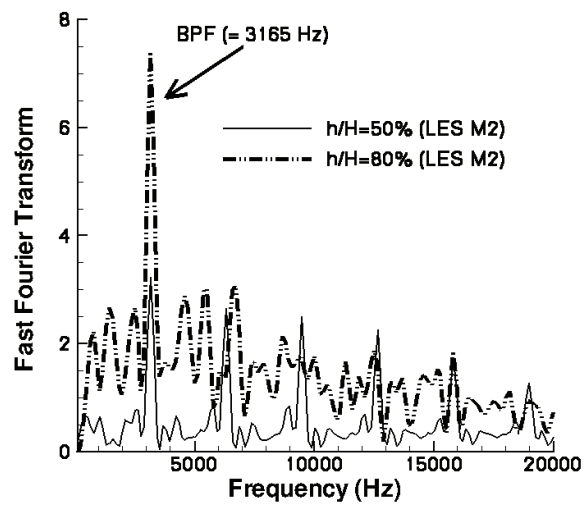

(b)

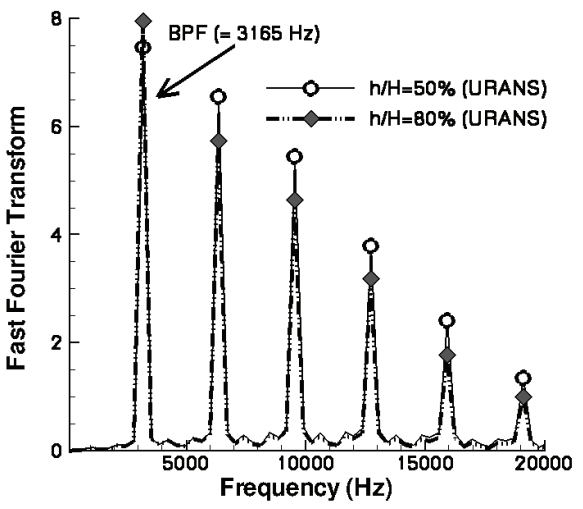

Figure 11: Fast Fourier Transform of axial velocity signals at rotor/stator interface $(x=$ $75 \mathrm{~mm}$ ), at $h / H=50 \%$ and $h / H=80 \%$ : (a) LES and (b) URANS. The probes are located in the middle of a stator passage, at mid-distance from the vane leading edges.

- the energy contained in the BPF is only $45 \%$ of the BPF energy estimated with URANS,

- the energy of the fifth harmonic represents $40 \%$ of the BPF one (instead of $20 \%$ in the case of URANS),

- turbulence is distributed over a large broadband frequency range without any visible dominant frequency.

Close to the casing $(h / H=80 \%)$ :

- the energy contained in the BPF increases by $130 \%$ compared to midspan,

- the energy related to the harmonics of the BPF is diminished compared to mid-span, 
- the amplitude of some frequencies which are not correlated to the BPF in the range $[0,2 \times B P F]$ is of the same order of magnitude than the BPF harmonics.

The analysis of the LES results is completed using Power Spectrum Density (PSD) representations of axial velocity signals, at four spans: $h / H=$ 50\%, 80\%, 90\% and 95\%, Fig. 12. At mid-span, the results corroborate those obtained with the FFT: most of the energy is associated to the BPF and its harmonics (at this span, the use of a URANS method is thus pertinent to estimate the level of unsteadiness). When moving closer to the casing, a part of the unsteadiness is transferred from the BPF (and its harmonics) to turbulent flow patterns. At $h / H=80 \%$ and $h / H=90 \%$, frequencies uncorrelated with BPF develops, Fig. 12(b-c): frequency $f=8,700 \mathrm{~Hz}$ (and its harmonic $f=15,800 \mathrm{~Hz}$ ) is found to be correlated to an axial pulsation of the tip leakage flow. At $h / H=95 \%$, the influence of the BPF is increased compared to other spans, Fig. 12(d), and the frequencies uncorrelated with the BPF $(f=8,700 \mathrm{~Hz}$ and its harmonic $f=15,800 \mathrm{~Hz})$ contain now more energy than the BPF harmonics.

\section{ANALYSIS OF TRANSITION MECHANISMS IN THE STATOR}

The flow at the rotor/stator interface is seen as the inflow condition for the stator. In the case of transitional flows, it is very important to represent the main features of turbulence (at least, turbulent intensity and typical length scales) to correctly predict the location of transition [17, 9]. 
(a)

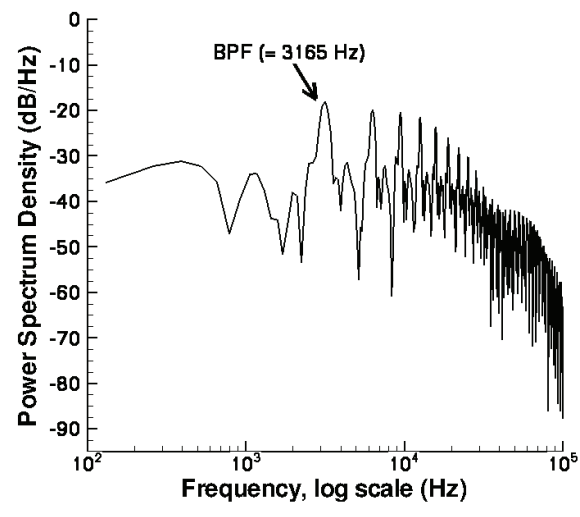

(c)

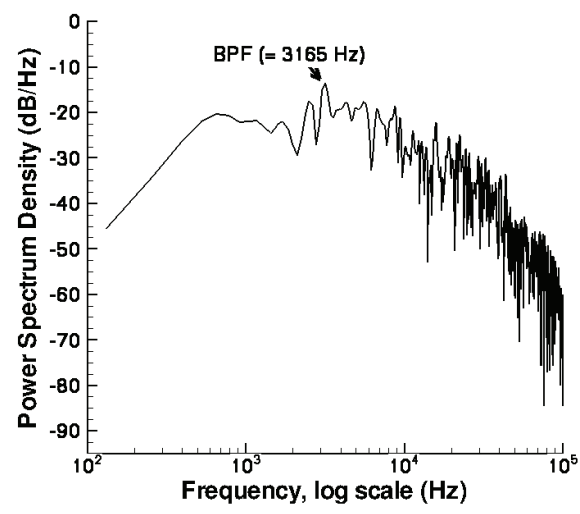

(b)

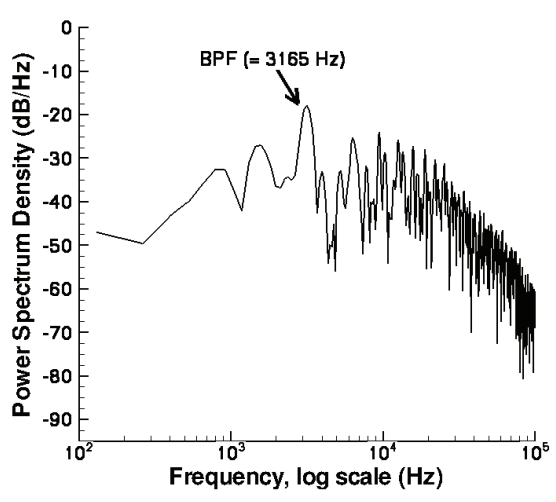

(d)

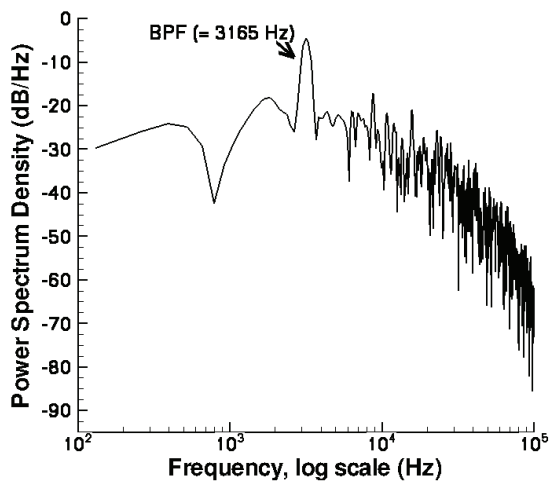

Figure 12: Power Spectrum Density of axial velocity signals at the rotor/stator interface ( $x=75 \mathrm{~mm}$, LES results): a) $h / H=50 \%$, b) $h / H=80 \%$, c) $h / H=90 \%$ and d) $h / H=95 \%$.

The turbulent intensities $T u_{i}=\frac{\sqrt{{\overline{W_{i}^{\prime}}}^{2}}}{\|W\|}$ are compared to available LDV measurements [25] in Table $3 . W_{i}$ is evaluated in the reference frame of the stator. LES predicts the strongest turbulent intensity in the azimutal direction, $T u_{\theta}=8.5 \%$, compared to axial and radial turbulent intensities, resp. 
$T u_{x}=5.5 \%$ and $T u_{r}=4.5 \%$. The value is in good agreement with the experimental data in the azimuthal direction $\left(T u_{e x p, \theta}=8.4 \%\right)$ but not in the axial direction $\left(T u_{e x p, x}=9.8 \%\right)$. URANS is unable to predict the values of the individual components in the wake, however it gives the same order of magnitude for the mean turbulent intensity $\left(\overline{T u}=\left(T u_{x}+T u_{\theta}+T u_{r}\right) / 3=6.5 \%\right)$ than LES $(\overline{T u}=6.2 \%)$. Both URANS and LES also significantly underpredict the value of the freestream turbulent intensity $\left(\overline{T u}_{L E S} \approx \overline{T u}_{R A N S} \approx\right.$ $\left.1 \%<\overline{T u}_{\exp }=2.8 \%\right)$.

\begin{tabular}{|c|ccc|ccc|ccc|}
\hline & \multicolumn{3}{|c|}{ LES } & \multicolumn{3}{c|}{ RANS } & \multicolumn{3}{c|}{ Experiments } \\
\hline- & $T u_{x}$ & $T u_{\theta}$ & $T u_{r}$ & $T u_{x}$ & $T u_{\theta}$ & $T u_{r}$ & $T u_{x}$ & $T u_{\theta}$ & $T u_{r}$ \\
\hline Wake & $5.5 \%$ & $8.5 \%$ & $4.5 \%$ & $6.5 \%$ & $6.5 \%$ & $6.5 \%$ & $9.8 \%$ & $8.4 \%$ & N.A. \\
Passage & $1.1 \%$ & $0.7 \%$ & $0.3 \%$ & $0.7 \%$ & $0.7 \%$ & $0.7 \%$ & $2.1 \%$ & $3.4 \%$ & N.A. \\
\hline
\end{tabular}

Table 3: Estimation of the phase and time-averaged turbulent intensity components $T u_{i}$ at mid-span $(h / H=50 \%)$ of the rotor/stator interface $(x=78 \mathrm{~mm})$. Data are evaluated in the reference frame of the stator.

Such inaccurate prediction of the mean turbulent intensity is disappointing for LES. Many reasons can explain this result: inaccurate comparison method or numerical simulation (or both). First, the turbulent fluctuation are measured at $2.9 \%$ of the stator chord upstream of the leading edge (in a plane where experimental data are available), so the turbulence level is very sensitive to the location of the measurement plane. Then, the grid is maybe not sufficiently fine and/or not adapted to the subgrid scale model, especially in the azimuth: wakes are moving in the azimutal direction so automatic grid refinement should be necessary (otherwise the grid should be significantly re- 
fined, leading to a serious overcost). As mentioned in the companion paper, the transport of the inflow turbulence (from the rotor inlet) is also questionable (inlet boundary condition and unsufficient grid refinement at the rotor inlet). As a consequence, the SGS model acts in the wake region, where the viscosity ratio $\nu_{S G S} / \nu$ reaches values around 20, as shown in Fig. 13. This is a consequence of the previous point but there is also a lack of studies in the literature about SGS models adapted to the propagation of turbulent wakes.

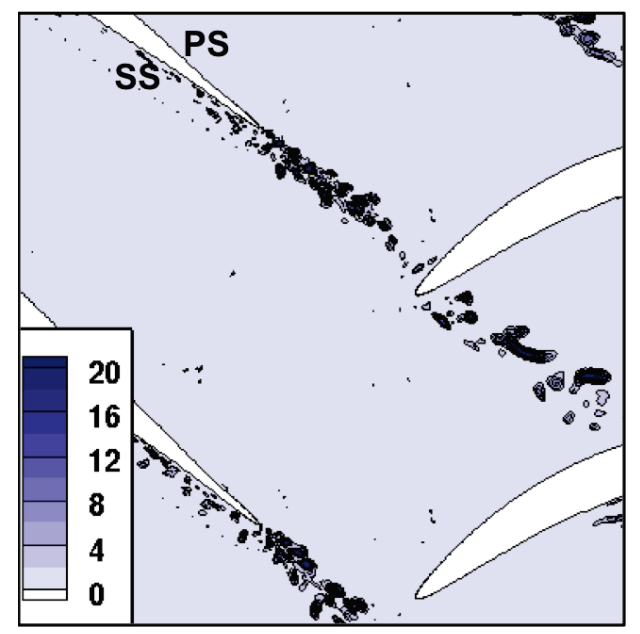

Figure 13: Close view of the instantaneous flow field in the vicinity of the rotor wakes, colored with the viscosity ratio $\nu_{S G S} / \nu$, from LES data at mid-span $(h / H=50 \%)$.

Except incoming rotor wakes, many mechanisms are in competition to trigger the transition of boundary layers in turbomachinery: free stream turbulence, adverse pressure gradient and flow acceleration. Mayle [19] proposes a classification of these transition mechanisms, Fig. 14(a), with respect to the momentum thickness Reynolds number $R e_{\theta}$ and the acceleration parameter $K$ defined as 


$$
K=\frac{\nu}{W_{s}^{2}} \frac{d W_{s}}{d S},
$$

where $\nu$ is the viscosity, $S$ the curvilinar abscissa and $W_{s}$ the streamwise component of the time-averaged velocity. The acceleration parameter $K$ is evaluated on the suction side of the stator, Fig. 14(b). From the leading edge to $S / C=0.05, K$ is higher than $3 \cdot 10^{-6}$ (i.e. the critical value to allow relaminarization). It is then close to 0 from $S / C=0.05$ to $S / C=0.30$ and then it is negative until the trailing edge. As shown in Fig. 7, the momentum thickness Reynolds number $R e_{\theta}$ is lower than 500 in the vicinity of the stator leading edge. Indeed, based on the data reported in Fig. 14(a), the transition should be of bypass type close to the leading edge and of separation-induced type after $S / C=0.30$. Relaminarization is also possible in the region from $S / C=0$ to $S / C=0.05$ (where $K>3.10^{-6}$ ).

The turbulent kinetic energy $k$ contained in the stator boundary layers is plot at $h / H=50 \%$, Fig. 15, and at $h / H=80 \%$, Fig. 16. To be compared with URANS data, all LES results are phase-averaged, using the rotor blade passing period. LES shows a complex flow pattern of wake-induced transitional strips and calmed flow, with evidences of turbulence decay, especially on the suction side.

On the pressure side, the transition starts to be periodic, induced by the passage of rotor wakes (after the wake passing, the flow come back to a laminar state). Close to the leading edge, the time during which the boundary 
(a)

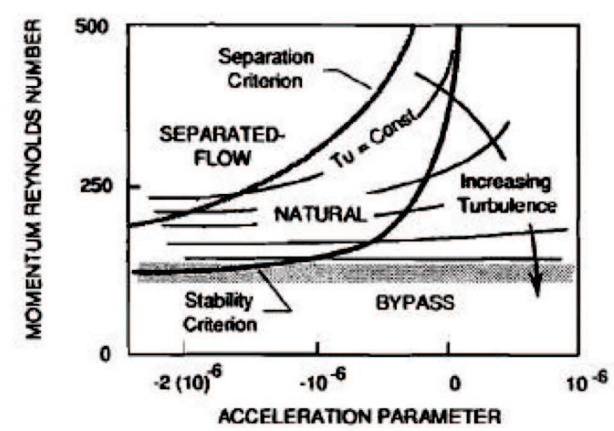

(b)

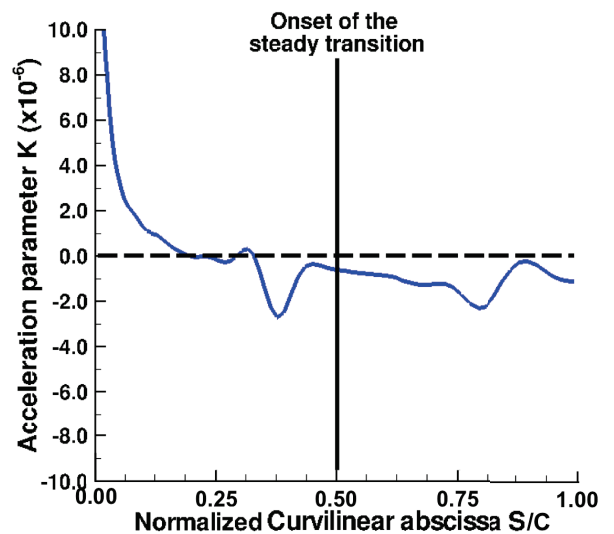

Figure 14: (a) Classification of transition phenomena with respect to the Reynolds number $R e_{\theta}$ and the acceleration parameter $K$, as proposed by Mayle [19] and b) estimation of the acceleration parameter $K$ in the present configuration, on the stator suction side, at $h / H=50 \%$. Relaminarization can occur for $K>3 \cdot 10^{-6}$.

layer is turbulent is more important by $50 \%$ with URANS than LES, mainly because the URANS wakes are thicker. Then, both URANS and LES find a steady transition point around $S / C=0.25$.

On the suction side, URANS predicts the same transition process than on the pressure side: first a periodic transition induced by incoming wakes before to reach a quasi-steady transition point induced by a local boundary layer separation at $S / C=0.50$ (the axial position of the separation is influenced by the rotor wakes passing, as shown in Fig. 15). However, while relaminarization is permitted by the transition model [15], it does not occur in the URANS simulation. LES shows first a region from the leading edge to $S / C=-0.40$ where the flow is periodically turbulent (like URANS) and then 
a second region from $S=-0.40$ to $S / C=-0.50$ where the flow is laminar (incoming wakes don't have any influence on the state of boundary layers at this location). Data presented in Fig. 14(b) shows a strong acceleration at this location so it tends to delay transition, as reported in a previous work for another compressor [10]. Actually, transition is triggered on the suction side at $S / C=0.50$ due to a laminar separation bubble.

Boundary layer transition on the stator vane is driven by two mechanisms: the transition induced by periodic incoming wakes and the quasi-steady transition induced by a laminar separation bubble. This behavior is similar to what has been experimentally reported by Hobson et al. for a compressor vane at a similar Reynolds number [11].

(a)

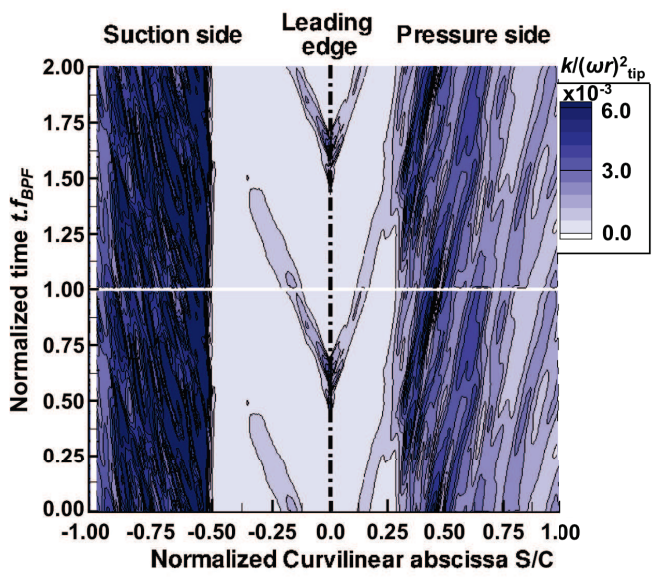

(b)

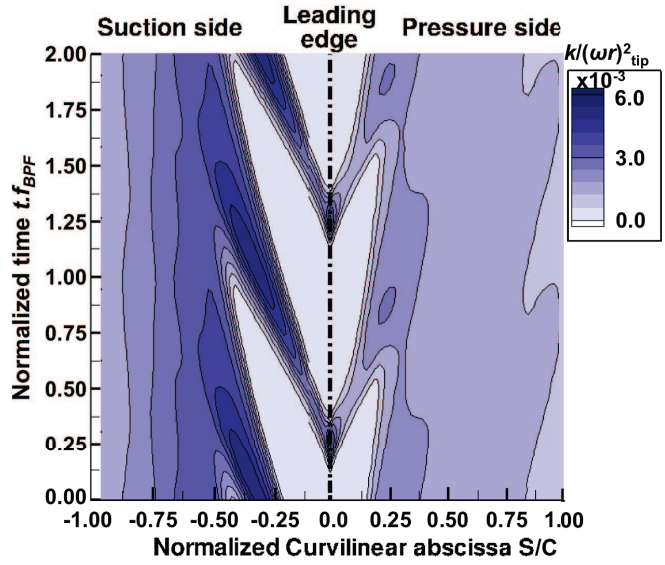

Figure 15: Evolution of the turbulent kinetic energy $k$ inside the stator boundary layer at a wall distance of $100 \mu m(n / \bar{\delta} \approx 0.03)$ at $h / H=50 \%$ : a) LES and b) URANS. Values of $k$ larger than 0 corresponds to a turbulent boundary layer.

Close to the casing, the same transition mechanisms are observed, but 
the transition is also influenced by the tip leakage flow, Fig. 16. LES shows a second peak of turbulent activity at the leading edge, after the rotor wake passing. The tip leakage flow induces a periodic transition, both on suction and pressure sides. URANS also indicates that the tip leakage flow induces a periodic transition, but only on the pressure side and after $S / C=0.10$. This difference relies on the trajectory of the tip leakage flow, which is different in URANS and LES. The suction side is not affected by the tip leakage flow because the wakes preferentially migrate towards the pressure side.

(a)

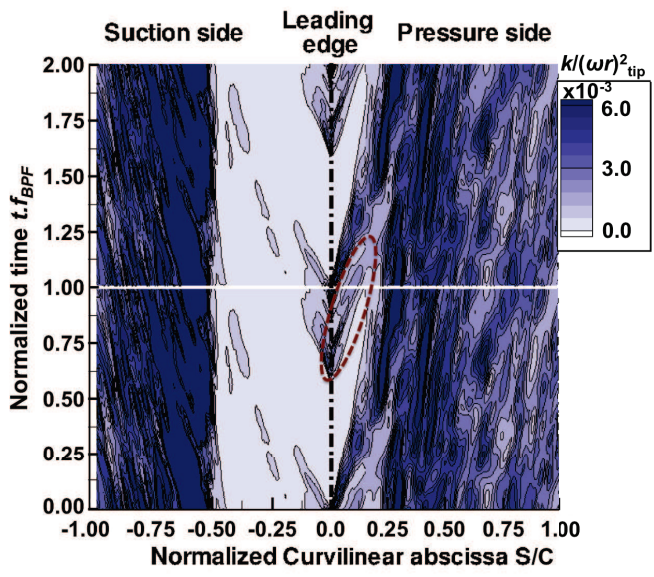

(b)

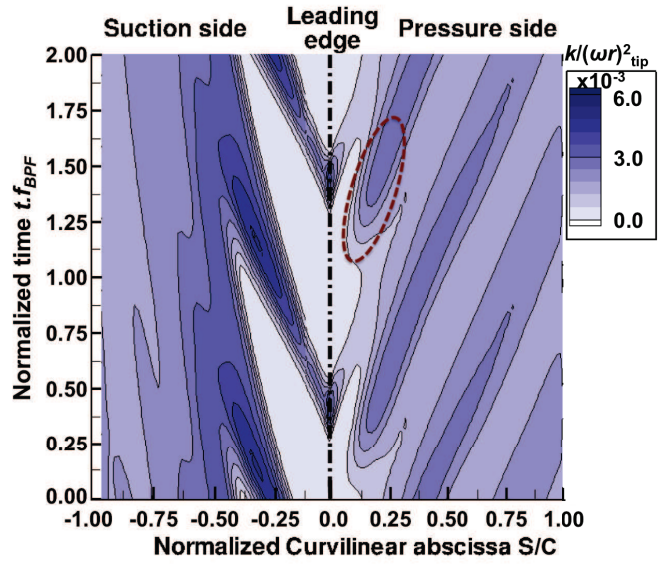

Figure 16: Evolution of the turbulent kinetic energy $k$ inside the stator boundary layer at a wall distance of $100 \mu m(n / \bar{\delta} \approx 0.03)$ at $h / H=80 \%$ : a) LES and b) URANS. Values of $k$ larger than 0 corresponds to a turbulent boundary layer. The dotted circle indicates the location of the tip leakage flow. 


\section{CONCLUSION}

This paper describes the analysis of URANS and LES database in a stage of an axial compressor, which operates at operating conditions relevant to industrial applications (Mach number $M \approx 0.53$ and Reynolds number $R e=$ $\left.7 \times 10^{5}\right)$. The following points summarize this study:

- both LES and URANS show that transition does not occur at the blade and vane leading edges, as it is usually assumed in most CFD calculations,

- comparison with experiments shows that numerical simulations (URANS and LES) underestimate the turbulent intensity at the rotor/stator interface, especially the axial component. As a consequence, the turbulent flow at the entrance of the stator is not correctly represented, which can affect the transition of stator boundary layer (rotor wake-induced transition),

- the spectral analysis of the unsteady flow at the rotor/stator interface points out that LES predicts frequencies uncorrelated with the BPF in the casing region, which are related to the tip leakage flow, while URANS only predicts harmonics of the blade passing frequency.

Actually a comparison of the transition processes between numerical data and experimental measurements is difficult for this test case. First the inflow conditions are not sufficiently known (turbulent intensity and length scales). 
It is thus mandatory for future researches based on LES and URANS to consider test case with sufficient measurements to analyze detailed physical mechanisms such as those involved in the transition processes (for instance measurements of the turbulent kinetic energy in the boundary layers). This work shows that LES helps in the understanding of complex physics, but it is still far to be predictive for turbomachinery flows. Wall-resolved LES data can be used to provide guidelines to develop wall models (including for LES), which represent a good accuracy/cost ratio, especially in the context of industrial design.

\section{Acknowledgment}

This work has benefited from the help of a lot of people. First, many thanks to H. Miton from Institut Jean Le Rond d'Alembert for providing experimental data. The author is also grateful to SAFRAN (with a special mention to M. Dumas and G. Leroy for their constant help and support). Thanks also to Pr. M. Manna (University of Naples) for suggesting some of the post-processings performed in this work. The author also thank the CFD team of CERFACS (with special thanks to J.-F. Boussuge and F. Sicot for reading the manuscript and T. Leonard and A. Gomar for their help on post-processing). This work has benefited from CERFACS internal and GENCI-TGCC computing facilities (under the project gen6074). ONERA also provided help and support for the CFD code elsA. These supports are greatly acknowledged. Actually, the author would like to express his sympa- 
thy and friendship to the turbomachinery team of LMFA at Ecole Centrale de Lyon. This paper is dedicated to Pr. Francis Leboeuf.

\section{References}

[1] S. C. Back, G. V. Hobson, S. J. Song, and K. T. Millsaps. Effects of reynolds number and surface roughness magnitude and location on compressor cascade performance. J. Turbomach., 134(5), 2012.

[2] A. Benyahia and R. Houdeville. Transition prediction in transonic turbine configurations using a correlation-based transport equation model. Int. J. of Engineering Systems Modelling and Simulation, 3(1):36-45, 2011.

[3] R. Bhaskaran and S. K. Lele. Large eddy simulation of free stream turbulence effects on heat transfer to a high-pressure turbine cascade. J. of Turbulence, 11(6), 2010.

[4] J. P. Bons. A review of surface roughness effects in gas turbines. $J$. Turbomach., 132(2), 2010.

[5] L. Cambier, S. Heib, and S. Plot. The Onera ElsA CFD software: Input from research and feedback from industry. Mechanics and Industry, 14:159-174, 2013.

[6] T. M. Faure, G.-J. Michon, H. Miton, and Vassilieff. Laser doppler 
anemometry measurement in an axial compressor stage. J. Propulsion and Power, 17(3), 2001.

[7] N. Gourdain. Prediction of the unsteady turbulent ow in an axial compressor stage. part 1: comparison of unsteady rans and les data with experiments. J. Computer and Fluids, submitted.

[8] N. Gourdain, L. Gicquel, M. Montagnac, O. Vermorel, M. Gazaix, G. Staffelbach, M. Garcia, J-F. Boussuge, and T. Poinsot. High performance parallel computing of flows in complex geometries - part 1: Methods. J. of Computational Sciences and Discovery, 2(015003), 2009.

[9] N. Gourdain, L. Y. M. Gicquel, and E. Collado. Comparison of RANS and LES for prediction of wall heat transfer in a highly loaded turbine guide vane. J. Propulsion and Power, 28(2):423-433, 2012.

[10] A. D. Henderson and G. J. Walker. Observations of transition phenomena on a controlled diffusion compressor stator with a circular arc leading edge. J. Turbomachinery, 132(3), 2010.

[11] G. V. Hobson, D. J. Hansen, D. G. Schnorenberg, and D. V. Grove. Effect of Reynolds number on separation bubbles on compressor blades in cascade. J. Propulsion and Power, 17(1):154-162, 2001.

[12] M. Jahanmiri. Boundary layer transitional flow in gas turbines. Technical Report 2011:01, Chalmers University of Technology, 2011. 
[13] A. Jameson. Time dependent calculations using multigrid, with applications to unsteady flows past airfoils and wings. In 10th AIAA Computational Fluid Dynamics Conference, paper 1596, 1991.

[14] J. Katz and A. Plotkin. Low-speed aerodynamics. Cambridge Aerospace Series, 2001.

[15] R. B. Langtry. A Correlation-Based Transition Model using Local Variables for Unstructured Parallelized CFD codes. PhD thesis, Stuttgart University, 2006.

[16] R. B. Langtry, F. R. Menter, S. R. Likki, and Y. B. Suzen. A correlationbased transition model using local variables - part 2: Test cases and industrial applications. J. Turbomach., 128(3), 2006.

[17] M. Manna, C. Benocci, and E. Simons. Large Eddy Simulation of turbulent flows via domain decomposition techniques. part 1: theory. Int. J. Num. Meth. Fluids, 48(4), 2005.

[18] M. Manna and A. Vacca. Effects of the transverse curvature on the statistics of fully developed turbulent flow in an annular pipe. Int. J. Rotating Machinery, 8(5):353-360, 2002.

[19] R. E. Mayle. The role of laminar-turbulent transition in gas turbine engines. J. Turbomach., 113(4), 1991.

[20] W. A. McMullan and G. J. Page. Towards large eddy simulation of gas turbine compressors. Progress in Aerospace Sciences, 52:30-47, 2012. 
[21] F. R. Menter. Two-equation eddy-viscosity turbulence models for engineering applications. AIAA J., 32(8), 1994.

[22] F. R. Menter, R. B. Langtry, S. R. Likki, and Y. B. Suzen. A correlationbased transition model using local variables - part 1: Model formulation. J. Turbomach., 128(3), 2006.

[23] V. Michelassi, J. G. Wissink, J. Frohlich, and W. Rodi. Large-eddy simulation of flow around low-pressure turbine blade with incoming wakes. AIAA J., 41(11):2143-2156, 2003.

[24] V. Michelassi, J. G. Wissink, and W. Rodi. Direct numerical simulation, large eddy simulation and unsteady Reynolds-averaged NavierStokes simulations of periodic unsteady flow in a low-pressure turbine cascade: A comparison. Proceedings of the Institution of Mechanical Engineers, Part A: Journal of Power and Energy, 217(4):403-411, 2003.

[25] G.-J. Michon, H. Miton, and N. Ouayahya. Unsteady three-dimensional off-design velocity and reynolds stresses in an axial subsonic compressor. J. Propulsion and Power, 21(6), 2005.

[26] F. Nicoud and F. Ducros. Subgrid-scale stress modelling based on the square of the velocity gradient. Flow, Turb. and Combustion, 62(3):183-200, 1999.

[27] H. Nishikawa, M. Rad, and P. Roe. A third-order fluctuation splitting 
scheme that preserves potential flow. In 15th AIAA Computational Fluid Dynamics Conference, paper 2001-2595, 2001.

[28] U. Piomelli and E. Balaras. Wall-layer models for Large-Eddy Simulations. Annu. Rev. Fluid Mech., 34, 2002.

[29] B. Raverdy, N. Liamis, I. Mary, and P. Sagaut. High-resolution largeeddy simulation of flow around low-pressure turbine blade. AIAA J., 41(3):390-397, 2003.

[30] F. Sicot, G. Dufour, and N. Gourdain. A time-domain harmonic balance method for rotor/stator interaction. J. Turbomach., 134(1), 2012.

[31] P. Tucker, S. Eastwood, C. Klostermeier, R. Jefferson-Loveday, J. Tyacke, and Y. Liu. Hybrid LES approach for practical turbomachinery flows - part 1: hierarchy and example simulations. J. Turbomach., 134(2), 2012.

[32] P. Tucker, S. Eastwood, C. Klostermeier, H. Xia, P. Ray, J. Tyacke, and W. Dawes. Hybrid LES approach for practical turbomachinery flows part 2: further applications. J. Turbomach., 134(2), 2012.

[33] S. Yoon and A. Jameson. An LU-SSOR scheme for the Euler and NavierStokes equations. In 25th AIAA Aerospace Sciences Meeting, paper 0600, 1987. 